\title{
FISH ROE SAMPLE PREPARATION FOR SYNTHETIC FOOD DYES DETERMINATION BY HPTLC
}

\author{
DORINA CASONI ${ }^{a}$, MIHAELA BADEA ${ }^{b}$, \\ SIMONA CODRUTA AURORA COBZAC ${ }^{a *}$
}

\begin{abstract}
Food dyes are widely used in food products to offset the colour loss. To prevent fraud in the food industry, to ensure food safety and consumer health protection, it is necessary to implement fast, accurate and reliable methods for the analysis of dyes. A relatively fast method based on high-performance thin-layer chromatography (HPTLC) - photodensitometry was developed and applied to determine two synthetic food dyes (Sunset Yellow - E 110 and Ponceau 4R - E 124) in fish roe. TLC separation was carried out on silica gel plates, using the mixture isopropyl alcohol-ammonia $(2: 1, V / V)$ as mobile phase. Good separation of the dyes was achieved, the $R_{f}$ values being 0.39 for $\mathrm{E} 110$ and 0.12 for E124, respectively. Due to the complexity of the matrix, sample preparation was performed into two steps: (i) extraction by ultrasound-assisted extraction with methanol-ammonia $(1: 1$, V/V) and (ii) purification of the extract by ion-pair solid phase extraction (IP-SPE) on ChromaBond RP-18E cartridges. For both dyes, the overall recovery for the sample preparation step was higher than $91 \%$, the relative standard deviation being less than 3.5\%. The procedure was applied for E110 and E124 determination from a "red caviar" sample with the declared content of dyes.
\end{abstract}

Keywords: Food synthetic dyes, roe fish, ultrasound-assisted extraction (UAE), ion-pair solid phase extraction (IP-SPE), HPTLC

\section{INTRODUCTION}

The evolution of human society has caused increasing consumer complaint regarding food quality. The long experience on food demonstrates

\footnotetext{
a Babeş-Bolyai University, Faculty of Chemistry and Chemical Engineering, 11 Arany Janos str., RO-400028, Cluj-Napoca, Romania

b Transilvania University of Brasov, Faculty of Medicine, 29 Eroilor Blvd, 500036, Brasov, Romania

*Corresponding author e-mail: simona.cobzac@ubbcluj.ro
} 
that the nutrition problem is more complex than the simple food-consuming act. The scientific studies have pointed out that the concept of food quality should be improved by taking into account all of its four aspects: energetic, biological, hygienic and psycho-sensorial [1]. One of the most important sensory qualities of a food product is the colour, frequently related to freshness and good taste. This aspect determines the producers to find solutions to produce more and more attractive food. Due to their instability, the natural dyes were replaced with synthetic food dyes (SFDs), which are cheaper, brighter, and stable. Food synthetic colorants are complex organic compounds derived from coal tar and petroleum that are classified according to their chemical structure (azo, triphenylmethane, indigo, etc.) and colour (yellow, orange, red, etc.).

Recent studies concerning the influence of SFDs on human organism revealed their neurotoxicity, genotoxicity and carcinogenicity. Azo dyes can be decomposed in the intestine to aromatic amines causing headaches and hyperactivity, and also they may have immunomodulatory effects even at a non-cytotoxic dose [2]. Due to these toxic effects, EU legislation has elaborated regulations that establish a list of food additives, which include the approved SFDs and their conditions of use [3,4].

As there is a growing need for fast, sensitive and accurate analytical methods to determine SFDs in different types of food, researchers have also focused on this topic [5]. Due to their spectral properties, dyes can be easily determined by spectrophotometric methods [6]. Complex dyes mixtures can be resolved by multivariate calibration [7] or spectra interpretation with the aid of chemometric computations such as classical least squares (CLS), principal component regression (PCR), partial least squares (PLS) and hybrid linear analysis (HLA) [8]. Spectrophotometric improved instruments for SFDs determination were also reported [9]. The most used technique for SFDs determination is chromatography which allows separation, identification and quantification in one single run. Usually, high-performance liquid chromatography with diode array detection (HPLC-DAD/PAD) [10, 11] and high-performance liquid chromatography coupled with mass spectrometry (HPLC-MS) $[12,13]$ are used. Another employed technique for SFDs determination is thin layer chromatography (TLC). The difficulty of this technique consists in optimization of chromatographic conditions regarding the selection of the stationary phase and an appropriate mobile phase. Usually, silica gel plates were used for separation. Various mobile phases were reported in the literature [14-16]. Plate evaluation was performed classical by scanning the plate at an appropriate wavelength or digital image processing [17-19]. 
Sample preparation is the bottleneck of an analysis. In the TLC technique, partial removal of the interferences (sugars, fats) can cause the blurring of chromatographic spots. Preconcentration and purification of liquid samples can be achieved by liquid-liquid microextraction [20] or dispersive liquid-liquid microextraction [21]. Solid-phase extraction is another technique usualy applied for preparation of liquid sample. The retention of SFDs is performed by using different sorbents such as alumina [22, 23], polyamide $[10,19,22]$, C18 [14, 19], aminopropyl modified silica [6], hydrophilic-lipophilic balanced polymers (HLB) [12] and anion exchangers [22]. Different liquid-solid extraction techniques were also employed to extract SFDs from solid matrices, ranging from classical ones such as magnetic stirring to modern ultrasoundassisted extraction [24] and accelerated solvent extraction [25], respectively. The touchstone is the selection of those extraction conditions that can assure an exhaustive extraction of the analytes.

According to our knowledge only few studies have been published for SFDs determination in samples with high content of protein and lipid [26, 27]. Based on the above consideration the aim of this paper is development of a new method fpr determination of Sunse Yellow - E110 (SY) and Ponceau 4 R - E124 (P4R) in fish roe and red caviar using ultrasound-assisted extraction (UAE) and ion-pair solid phase extraction (IP-SPE) for sample preparation followed by high-performance thin-layer chromatography (HPTLC) analysis.

\section{RESULTS AND DISCUSSION}

\section{Evaluation of the analytical performance of the chromatographic method}

The chromatographic analysis of the dyes, carried out on HPTLC Silica gel G60 plates using the mixture isopropyl alcohol - ammonium hydroxide (2:1, $\mathrm{v} / \mathrm{v}$ ) as mobile phase, revealed a good separation of the analysed SFDs with a $R_{f}$ value of 0.39 for E110 and 0.12 for E124. The analytical performance of the chromatographic method was evaluated in terms of linearity range, limit of detection (LOD) and quantification (LOQ) (Table 1).

Table 1. Calibration curve equation for the studied food synthetic dyes

\begin{tabular}{|c|c|c|c|c|c|}
\hline SFD & $\begin{array}{c}\text { Calibration range } \\
\text { (ng/spot) }\end{array}$ & Equation & $\mathrm{R}^{2}$ & $\begin{array}{c}\text { LOD } \\
\text { (ng/spot) }\end{array}$ & $\begin{array}{c}\text { LOQ } \\
\text { (ng/spot) }\end{array}$ \\
\hline E 110 & $81.65-489.9$ & $\mathrm{Y}=97127 \mathrm{X}+5912.3$ & 0.9959 & 36.8 & 69.9 \\
\hline $\mathrm{E} 124$ & $117.45-704.70$ & $\mathrm{Y}=59669 \mathrm{X}+7454.5$ & 0.9935 & 24.3 & 46.5 \\
\hline
\end{tabular}




\section{Recovery studies}

The fish roe samples are very complex solid matrices considering their high content in lipids, proteins and salt. Moreover, in this particular case, sample preparation is more difficult due to the high affinity of synthetic food dyes for proteins [28]. Usually, sample preparation of a solid matrix is performed in two steps: (i) analyte isolation from the solid using a solvent or a mixture of solvents which should ensure exhaustive extraction of the analytes and (ii) extracts purification to remove the interferences using liquid-liquid extraction or solid-phase extraction (SPE). As the number of processing steps increases, the sample preparation has a larger contribution to the overall analysis error. Anyhow, each step must be carefully optimized because only in those conditions the error and the relative standard deviation can be diminished. Moreover, to obtain reliable and robust sample preparation, it is preferable to carry out the studies on the different sample and at various concentration levels of the analytes.

Taking in account the general considerations mentioned above, the recovery studies were carried out on two types of fish roe - herring and trout, selected based on their properties: herring roe having a white colour it was easier to observe the extraction of the dye by visual observation, and trout roe because of the similar aspect with the red caviar sample. On the other hand, the recovery studies were carried out on two different concentration levels.

\section{SPE recovery study}

For the recovery studies, liquid matrices obtained by extraction from fihs roe (herring) free of dyes were used. These extracts were spiked with E110 and E124 at a concentration level of $40.825 \mu \mathrm{g} / \mathrm{mL}$ and $58.725 \mu \mathrm{g} / \mathrm{mL}$. Two approaches for extract purification using SPE were studied. The first one consists of dyes retention from acidic solution (acetic acid aqueous solution $2 \%$ ). Good recoveries values were obtained (Table 2), but when the extract was evaporated, a lipids residuum was observed.

The second procedure was based on the retention of the ion-pair compound formed by the SFDs with CTAB. By applying this procedure, several advantages have been achieved. First, the retention of the dyes on C18 sorbent, through a hydrophobic retention mechanism, was improved. Narrow adsorption zone was obtained because of the strong interaction between hexadecyl radical of the ion-pair compound and the octadecyl chains of the sorbent. Second, during retention, CTAB was also adsorbed on the sorbent surface. This imparts a charged character to the sorbent surface, and lipids were no longer retained. All these contribute to obtaining a cleaner extract and high recovery values (Table 2 ). 
Table 2. Recovery values of dyes obtained by SPE

\begin{tabular}{|c|c|c|c|c|c|}
\hline \multirow{2}{*}{ Sample } & Purifying method & \multicolumn{2}{|c|}{ Recovery (\%) } & \multicolumn{2}{|c|}{ RSD (\%) } \\
\cline { 3 - 6 } & & E110 & E124 & E110 & E124 \\
\hline \multirow{2}{*}{$\begin{array}{c}\text { Spiked } \\
\text { extract of } \\
\text { herring roe }\end{array}$} & $\begin{array}{c}\text { SPE } \\
\text { (acid environment) }\end{array}$ & 97.42 & 97.09 & 1.06 & 1.31 \\
\cline { 2 - 6 } & $\begin{array}{c}\text { SPE } \\
\text { (ion-pair with CTAB) }\end{array}$ & 98.53 & 97.78 & 0.70 & 0.94 \\
\hline
\end{tabular}

\section{Overall recovery study for sample preparation}

The studies of SFDs recovery were carried out on spiked roe samples at two concentration levels using ultrasound-assisted extraction. The mixtures water-ammonium hydroxide (Method I and II) and methanol-ammonium hydroxide (Method III and IV) were used as extraction system. Two purification techniques, liquid-liquid and SPE using a C18 sorbent, were evaluated. The extraction agent used for method I and II was selected considering that SFDs are very soluble in water and that ammonium hydroxide can break the bond analyte-substrate. After centrifugation, when the removal of the residual lipids was attempted by liquid-liquid extraction (Method I), a three-phase system was formed. When SPE was employed for purification (Method II) the cartridge becomed quickly clogged. It is possible that during sonication, when high shear forces are present, the cell membrane to be advanced fragmented. Consequently, the extraction system was changed; water being replaced with methanol (Method III). Due to a lower value of the heating capacity ratio, the pressure produced by the acoustic waves in the new extraction system was smaller. The complete extraction was achieved after three extraction cycles. After HPTLC separation, tailed spots were observed. These could be explained by the presence of interferences. A purification step by SPE was implemented in the sample preparation protocol (Method IV). Based on the recovery values obtained using extraction Method IV (Table 3 ) the IP-SPE variant was chosen for pre-treatment of the red caviar sample.

\section{Synthetic food dyes determination from red caviar sample}

The determination of dyes content was performed using ultrasoundassisted extraction with methanol:ammonia mixture as extraction system followed by IP-SPE (Method IV). The extraction was carried out on non-spiked red caviar samples $(\mathrm{C} 0)$ and also on spiked samples at two concentration levels $(\mathrm{C} 1 ; \mathrm{C} 2)$. The analytes were identified by comparing the retention factor 
$\mathrm{R}_{\mathrm{f}}$ and spot colour with those of the SFDs standard spots. The calibration curve method was used for the determination of dyes amount in red caviar. The initial amount of SFDs for spiked samples was computed as diference between the determined quantity and the added one.

Table 3. Recovery of the dyes extracted from spiked fish roe samples by Method IV (extraction agent methanol-ammonia $(1: 1, \mathrm{v} / \mathrm{v})$ and extract purification by SPE)

\begin{tabular}{|c|c|c|c|}
\hline \multirow{2}{*}{$\begin{array}{c}\text { Sample } \\
\text { (spiking level) }\end{array}$} & $\begin{array}{c}\text { Purifying } \\
\text { method }\end{array}$ & \multicolumn{2}{|c|}{ Recovery (\%) } \\
\cline { 3 - 4 } & SPE & E110 & E124 \\
\hline Herring roe (L1) & SPE & 91.47 & 91.20 \\
\hline Herring roe (L2) & SPE & 87.24 & 85.98 \\
\hline Trout roe & SPE & 98.98 & 96.66 \\
\hline Herring roe (L1) & SPE & 93.48 & 91.87 \\
\hline Herring roe (L2) & SPE & 97.49 & 95.37 \\
\hline Trout roe & \multicolumn{2}{|c}{} \\
\hline
\end{tabular}

Table 4. Quantitative estimation of the synthetic dyes content in red caviar by using standard addition method at two concentration levels

\begin{tabular}{|c|c|c|c|}
\hline \multirow[t]{2}{*}{ No } & \multirow[t]{2}{*}{$\begin{array}{l}\text { Red caviar } \\
\text { sample }\end{array}$} & \multicolumn{2}{|c|}{$\begin{array}{c}\text { Determined amount (mean value } \pm \text { SD) } \\
(\mathrm{mg} / \mathrm{kg})\end{array}$} \\
\hline & & E110 & E124 \\
\hline 1 & \multirow{3}{*}{$\mathrm{CO}$} & \multirow{3}{*}{$195.51( \pm 7.96)$} & \multirow{3}{*}{$197.65( \pm 5.18)$} \\
\hline 2 & & & \\
\hline 3 & & & \\
\hline 4 & \multirow{3}{*}{ C1 } & \multirow{3}{*}{$192.46( \pm 6.41)$} & \multirow{3}{*}{$194.82( \pm 7.2)$} \\
\hline 5 & & & \\
\hline 6 & & & \\
\hline 7 & \multirow{3}{*}{$\mathrm{C} 2$} & \multirow{3}{*}{$191.90( \pm 8.36$} & \multirow{3}{*}{$193.69( \pm 7.47)$} \\
\hline 8 & & & \\
\hline 9 & & & \\
\hline
\end{tabular}

C0 - non-spiked sample; C1 - spiked sample $(40.825 \mu \mathrm{g} / \mathrm{mL}$ E110; $58.725 \mu \mathrm{g} / \mathrm{g}$ E124); C2 - spiked sample (81.65 $\mu \mathrm{g} / \mathrm{mL} \mathrm{E110;} 117.45 \mu \mathrm{g} / \mathrm{g} \mathrm{E124);} \mathrm{the} \mathrm{determined}$ amount was expressed as mean value \pm SD

In order to decide if there are significant differences between the determined concentration of SFDs in non-spiked (C0) and spiked (C1, C2) ttest was used for the statistical comparation of the mean values (Table 5). 
Table 5. Statistical parameters for comparison of results in non-spiked and spiked caviar samples

\begin{tabular}{|c|c|c|c|c|c|c|}
\hline \multirow[t]{2}{*}{ Grup } & \multicolumn{2}{|c|}{$\mathrm{CO}$} & \multicolumn{2}{|c|}{ C1 } & \multicolumn{2}{|c|}{ C2 } \\
\hline & t-value & $p$ & t-value & $p$ & t-value & $p$ \\
\hline \multicolumn{7}{|c|}{ SY } \\
\hline $\mathrm{CO}$ & - & - & 1.5750 & 0.1904 & 1.6462 & 0.1750 \\
\hline C1 & - & - & - & - & 0.2760 & 0.7961 \\
\hline \multicolumn{7}{|c|}{ P4R } \\
\hline $\mathrm{CO}$ & - & - & 2.2921 & 0.0837 & 1.6838 & 0.1675 \\
\hline C1 & - & - & - & - & 0.5699 & 0.5992 \\
\hline
\end{tabular}

C0 - non-spiked sample; C1 - spiked sample $(40.825 \mu \mathrm{g} / \mathrm{mL}$ E110; $58.725 \mu \mathrm{g} / \mathrm{g}$ E124); C2 - spiked sample (81.65 $\mu \mathrm{g} / \mathrm{mL}$ E110; $117.45 \mu \mathrm{g} / \mathrm{g} \mathrm{E124)}$

At a confidence interval of $95 \%$, a significance level of 0.05 and 4 degree of freedom, the critical t-value is 2.78 . Since the experimental t-value is smaller than critical value, null hypothesis (no significant differences) is accepted.

\section{CONCLUSION}

A fast, simple, and economically method was developed for the determination of SFDs from the fish roe. Sample preparation was achieved by using ultrasound-assisted extraction with methanol-ammonia $(1: 1, v / v)$ as extraction agent followed by IP-SPE extract purification using CTAB as an ionpairing reagent. TLC analyses were carried out on HPTLC Silica gel plates and isopropyl alcohol-ammonia $(2: 1, \mathrm{v} / \mathrm{v})$ as mobile phase. The extraction studies on SFDs in spiked roe samples showed an overall recovery value at least of $91.87 \%$ and a maximum relative standard deviation of $3.49 \%$. The proposed method was used for the determination of E110 and E124 in a red caviar sample, $193.29 \mathrm{mg} \mathrm{Kg}^{-1}$ and $195.39 \mathrm{mg} \mathrm{Kg}^{-1}$ being determined for $E 110$ and $E$ 124, respectively. Considering the studied dyes as a III-rd category food additive that permit a maximum combined limit of $300 \mathrm{mg} \mathrm{Kg}^{-1}$, the red caviar product cannot be considered adequate for consumers.

\section{EXPERIMENTAL SECTION}

\section{Reagents and chemicals}

Methanol (PubChem CID: 887), iso-propanol (PubChem CID: 3776), hexane (PubChem CID: 8058), acetic acid (PubChem CID: 176) and ammonium hydroxide (25\%) (PubChem CID: 14923) were purchased from Chemical Company 
(lași, România). Sunset yellow (PubChem CID: 6093232) and Ponceau 4R (PubChem CID: 54604869) were purchased from Fluka (Buchs, Switzerland). Cetyltrimethylammonium bromide (CTAB) (PubChem CID: 5974) was purchased from Merck (Hohenbrunn, Germany). All reagents were analytical grade. HPTLC Silica gel 60 plates $(20 \times 10)$ and ChromaBond C18 $(6 \mathrm{~mL} / 500 \mathrm{mg})$ cartridges were purchased from Macherey-Nagel (Duren, Germany).

Standard solutions of Sunset Yellow-E110 $(163.3 \mu \mathrm{g} / \mathrm{mL})$ and Ponceau $4 \mathrm{R}-\mathrm{E} 124(234.9 \mu \mathrm{g} / \mathrm{mL})$ were prepared by dissolving the appropriate amounts of dyes in methanol. For calibration curve, a 1:5 dilution of standard solution was used. The standard solutions were stored in darkness at $4^{\circ} \mathrm{C}$ until use. Acetic acid $2 \%$ and CTAB $0.02 \%$ aqueous solution were also prepared.

Experiments were carried out on two different samples of fish roe (herring and trout) free of dyes and on a red caviar sample with the declared content of synthetic colorants on the label. All these samples were purchased from the local supermarket.

\section{Equipments}

Sample preparation was performed by using an Elma Transsonic T310 sonication bath (Singen, Germany), a Hettich EBA20 centrifuge (Tuttlingen, Germany) and a drying stove Venticell BMT (Brno, Czech Republic). An IST VacMaster vacuum manifold was used for solid-phase extraction (Lund, Sweden). The samples were applied on the Silica gel plates using a Linomat 5 semiautomatic TLC applier (Camag, Switzerland). Plate evaluation was performed using a Dual-wavelength flying spot scanner Shimadzu CS-9000 (Shimadzu Scientific Instruments, Inc. Columbia, MD, USA).

\section{Sample preparation}

A blank extract of fish roe was obtained by ultrasound extraction of $2 \mathrm{~g}$ of herring roe three times with $10 \mathrm{~mL}$ of methanol-ammonium hydroxide $(25 \%)(1: 1, v / v)$. The collected extracts were centrifuged 10 minutes at 4500 $\mathrm{rpm}$, and the supernatant was evaporated and brought to $10 \mathrm{~mL}$ with methanol-water $(9: 1, v / v)$. This extract spiked with E110 and E124 at a concentration level of $40.825 \mu \mathrm{g} / \mathrm{mL}$ and $58.725 \mu \mathrm{g} / \mathrm{mL}$, respectively was further used for solid phase extraction purification studies.

Solid-phase extraction was performed using two different retention conditions, in an acid environment (acetic acid) and in the presence of ionparing reagent CTAB (IP-SPE). The sample $(1 \mathrm{~mL})$ subjected to SPE was diluted to $50 \mathrm{~mL}$ with acetic acid $(2 \%)$ or CTAB $(0.02 \%)$ solution. The SPE cartridge was conditioned with $5 \mathrm{~mL}$ methanol and washed with the aqueous solution of acetic acid or CTAB. The dyes retention was carried out at a flow 
rate of about $5 \mathrm{~mL} / \mathrm{min}$. After a washing step with acetic or CTAB solution, the cartridge was dried up for 10 min by passing an airflow. Elution was performed with $5 \mathrm{~mL}$ methanol-ammonium hydroxide $(25 \%)(10: 0.1, \mathrm{v} / \mathrm{v})$ at low flow rate $(1 \mathrm{~mL} / \mathrm{min})$. The extract was dried up and redissolved in $1 \mathrm{~mL}$ methanol-water $(9: 1, v / v)$. Triplicate samples were obtained with each procedure.

Dyes extraction from the spiked sample of roe was carried out both on herring and trout roe at two concentration levels L1 $(163.3 \mu \mathrm{g} / \mathrm{g} \mathrm{E} 110$; $234.9 \mu \mathrm{g} / \mathrm{g} \mathrm{E124)}$ and L2 (81.65 $\mu \mathrm{g} / \mathrm{g} \mathrm{E110;} 117.45 \mu \mathrm{g} / \mathrm{g}$ E124). There were investigated four different methodologies.

Method I consists of sonication with water-ammonia (1:1, v/v) mixture as the extraction agent. Three successive extractions with $15 \mathrm{~mL}$ extracting agent were carried out for 10 minutes at room temperature. The collected extracts were centrifuged at $4500 \mathrm{rpm}$ for 10 minutes, and the supernatant was purified by liquid-liquid extraction with hexane $(3 \times 15 \mathrm{~mL})$.

Method II was similar to that described before, except for the purification step, which was carried out by solid phase extraction instead of liquid-liquid extraction.

Method III consists of sample sonication with methanol-ammonia $(1: 1, v / v)$. The extraction was repeated three times with $15 \mathrm{~mL}$ extraction agent. The collected extracts were centrifuged for 10 minutes at $4500 \mathrm{rpm}$. The supernatant was evaporated, and residuum was dissolved in $1 \mathrm{~mL}$ of methanol-water $(9: 1, v / v)$.

Method IV was performed in the same condition as described above (Method III) but included a purification step by SPE.

\section{Analysis of the red caviar sample}

Analysis of red caviar sample was performed both on roe fish sample (C0) and on spiked samples at two concentration levels C1 $(40.825 \mu \mathrm{g} / \mathrm{g}$ E110; $58.725 \mu \mathrm{g} / \mathrm{g} \mathrm{E124)}$ and C2 (81.65 $\mu \mathrm{g} / \mathrm{g} \mathrm{E110;} 117.45 \mu \mathrm{g} / \mathrm{g} \mathrm{E124)}$ respectively. The extraction of the dyes was performed according to Method IV followed IP-SPE. The experiments were carried out in triplicates. The obtained extracts were further analysed by HPTLC.

\section{HPTLC analysis}

Chromatographic separation was performed on HPTLC Silicagel G60 plates. The samples were applied as $10 \mu \mathrm{L}$ spots for recovery studies and as $5 \mu \mathrm{L}$ for caviar samples. All samples were applied in triplicate. Plate development was performed in a normal saturated chamber using as mobile phase a mixture of isopropyl alcohol-ammonium-hydroxide $(25 \%)(2: 1, \mathrm{v} / \mathrm{v})$. 
After development, the plates were dried and evaluated by scanning at 485 $\mathrm{nm}$ and $515 \mathrm{~nm}$ for E 110 and E 124, respectively. In order to determine the equation of the calibration curve, spots of $2.5-15 \mu \mathrm{L}$ of 1:5 diluted standard solution were applied on the chromatographic plate. Since limit of detection (LOD) and limit of quantification (LOQ) depend on the quality of the calibration, they were computed based on the regression line and its confidence interval (Statistical Methods in Analytical Chemistry - SMAC soft 0.5).

\section{REFERENCES}

1. J.C. Griffiths, Food technol., 2005, 59, 38-44

2. A. Yadav, A. Kumar, A. Tripathi, M. Das, Toxicol. Lett., 2013, 217, 197-204

3. Official Journal of the European Union, L 295/1, Commission Regulation (EU) No 1129/2011 of 11 November 2011, amending Annex II to Regulation (EC) No $1333 / 2008$ of the European Parliament and of the Council by establishing a Union list of food additives, available at https://www.fsai.ie/uploadedFiles/ Reg1129_2011.pdf

4. Official Journal of the European Union, L 354/16, Regulation (EC) No 1333/ 2008 of the European Parliament and of the Council of 16 December 2008 on food additives, available at http://eur-lex.europa.eu/legal-content/EN/ALL/?uri= CELEX:32008R1333

5. K. Ntrallou, H. Gika, E.D. Tsochatzis, Foods, 2020, 9(58), 1-27

6. A.W. Sobanska, P. Jakubczyk, J. Pyzowski, E. Brzezinska, Acta Innovations, 2018, 27, 53-60

7. A.H. El-Sheikh, Y.S. Al-Degs, Dyes Pigm., 2013, 97, 330-339

8. Y.S. Al-Degs, Food Chem., 2009, 117, 485-490

9. M.H. Sorouraddin, A. Rostami, M.Saadati, Food Chem., 2011, 127, 308-313

10. S. Bonan, G. Fedrizzi, S. Menotta, E. Caprai, Dyes Pigm., 2013, 99, 36-40

11. W.A.S. Bento, B.P. Lima, A.P.S. Paim, Food Chem., 2015, 183, 154-160

12. F. Feng, Y. Zhao, W. Yong, L. Sun, G. Jiang, X. Chu, J. Chromatogr. B, 2011, 879, 1813-1818

13. P. Qi, Z. Lin, G. Chen, J. Xiao, Z. Liang, L. Luo, J. Zhou, X. Zhang, Food Chem., 2015, 181, 101-110

14. D. Casoni, A. Boldan, S.C. Cobzac, Stud. Univ. Babeş-Bolyai, Chem., 2012, 57(1), 83-92

15. F.I. de Andrade, M.I. Florindo Guedes, I.G. Pinto Vieira, F.N. Pereira Mendes, P.A. Salmito Rodrigues, C.S. Costa Maia, M.M. Marques Ávila, L. de Matos Ribeiro, Food Chem., 2014, 157, 193-198

16. S.C. Cobzac, D. Casoni. C. Sârbu, Stud. Univ. Babeş-Bolyai, Chem., 2010, 45(2), 227-235

17. F. Soponar, A.C. Mot, C. Sarbu, J. Chromatogr. A, 2008, 1188, 295-300 
18. S.C. Cobzac, D. Casoni, D. Pop, JPC-J Planar Chromatogr., 2012, 25, 542-547

19. S.C. Cobzac, D. Casoni, A.L. Fazakas, C. Sârbu, J. Liq. Chromatogr. Relat. Technol., 2012, 35, 1423-1443

20. O. Sha, X. Zhu, Y. Feng, W. Ma, Food Chem., 2015, 174, 380-386

21. H. Wu, J. Guo, L. Du, H. Tian, C. Hao, Z. Wang, J. Wang, Food Chem., 2013, $141,182-186$

22. J. Kirschbaum, C. Krause, H. Bruckner, Eur. Food. Res. Technol., 2006, 222, $572-579$

23. W.J. Li, X. Zhou, S.S. Tong, Q. Jia, Talanta, 2013, 105, 386-392

24. J.L. Tadeo, C. Sanchez-Brunete, B. Albero, A.I García-Valcárcel, J. Chromatogr. A, 2010, 1217, 2415-2440

25. O.G. Liao, W.H. Li, L.G. Luo, Anal. Chim. Acta, 2012, 716, 128-132

26. T. Zou, P. He, A. Yasen, Z. Li, Food Chem., 2013, 138, 1742-1748

27. G. Karanikolopoulos, A. Gerakis, K. Papadopoulou, I. Mastrantoni, Food Chem., 2015, 177, 197-203

28. A. Basu, G.S. Kumar, J. Hazard. Mater., 2014, 273, 200-206 
